\title{
A Proteção Jurídica das Crianças e dos Adolescentes
}

\section{Legal Protection of Children and Teenagers}

\section{RODRIGUES RODRIGUES}

Advogada, Especialista em Direito Civil e Empresarial, Mestranda em Direitos Fundamentais e Democracia pela Unibrasil.

Submissão: 17.02 .2014

Decisão Editorial: 15.05.2014,

RESUMO: 0 artigo analisa a proteção jurídica dispensada à criança e ao adolescente. Verifica-se, por meio de um breve histórico, no período do Brasil-Colônia, como a classe infantojuvenil era vista e tratada pela sociedade, pela família e pelo Estado naquela época. Analisa os principais diplomas nacionais e internacionais que atualmente tutelam os direitos das crianças e dos adolescentes considerando-os como sujeitos de direito. Por meio de dados estatísticos do IBGE e do Unicef, constata-se como a classe infantojuvenil está sendo respeitada no que tange aos seus direitos fundamentais, uma vez que a referida pesquisa quantitativa tem importância no sentido de mostrar a toda a sociedade a real situação da classe infantojuvenil, proporcionando uma maior reflexão a respeito dos problemas que ainda afligem muitas crianças e adolescentes brasileiros.

PALAVRAS-CHAVES: Crianças; adolescentes; sujeitos de direito.

SUMMARY: This article analyzes the legal protection given to children and to adolescents, it is verified through a brief historic overview on the period of Colonial Brazil as to how the young class was seen and treated by the society, family, and state. It also analyzes the main national and international diplomas that nowadays are in charge of the children and teenagers rights considering them as subjects of law. Through IBGE's and Unicef's statistics it is observed how the young class is being respected on their fundamental rights, since the referred statistics are important to demonstrate to the whole society the actual situation in which they are, providing then, a bigger outlook about the problems that still affect many Brazilian children and teenagers.

KEYWORDS: Children; teenagers; subjects of law.

SUMÁRIO: Introdução; 1 Breve histórico das crianças e adolescentes no Brasil Colônia; 2 Diplomas legais pertinentes aos direitos da criança e do adolescente; 2.1 Declaração de Genebra (1924); Declaração Universal dos Direitos da Criança e a Convenção Internacional dos Direitos da Criança; 2.2 Constituição Federal de 1988; 2.3 Estatuto da Criança e do Adolescente (Lei nº 8.069/1990); 3 A criança e 0 adolescente como sujeitos de direitos; Considerações finais; Referências.

\section{INTRODUÇÃO}

O presente artigo tem como objetivo principal analisar a proteção jurídica dispensada à classe infantojuvenil, analisando, neste contexto, os principais 
diplomas nacionais e internacionais que tratam dos direitos dessa classe, tendo em vista que tal classe por muito tempo não foi considerada como tal. Ao analisar historicamente a população infantojuvenil, constata-se que esta sempre foi marcada pela exclusão e pelo desamparo pela sociedade, família e Estado, isto é, encontrava-se sempre em segundo plano nas questões governamentais e familiares, diferentemente do que vem estabelecido hoje, cujo princípio da prioridade absoluta está presente na Constituição Federal e no Estatuto da Criança e do Adolescente.

Atualmente, as crianças e os adolescentes estão protegidos juridicamente, pois há uma intensa legislação tanto de âmbito nacional como internacional que dizem respeito aos direitos cabíveis a essa parcela da sociedade, bem como instrumentos jurídicos capazes de garantir que esses direitos sejam realmente efetivados no mundo dos fatos.

A Constituição Federal de 1988 foi de fundamental importância para a consolidação da proteção jurídica da população infantojuvenil, pois, por meio dessa Carta Política, reconheceu-se a criança e o adolescente como sujeitos de direito, bem como definiu a Doutrina da Proteção Integral como base de todo o ordenamento jurídico atinente à população infantojuvenil. Assim, as crianças e os adolescentes passam a ser vistos e considerados de fato como cidadãos e portadores de direitos fundamentais como qualquer pessoa adulta.

Em 1990, surge o Estatuto da Criança e do Adolescente para reafirmar os preceitos constitucionais da Carta Magna, a fim de que estes não se tornem letra morta no mundo jurídico, bem como estabelece mecanismos jurídicos para a efetivação dos direitos fundamentais inerentes à classe infantojuvenil.

Assim, atualmente as crianças e os adolescentes estão protegidos juridicamente, pois há uma intensa legislação tanto de âmbito nacional como internacional que diz respeito aos direitos cabíveis a essa parcela da sociedade, bem como instrumentos jurídicos capazes de garantir que esses direitos sejam realmente efetivados no mundo dos fatos.

Busca-se, por meio das legislações vigentes, salvaguardar os interesses da criança e do adolescente, pois, em épocas passadas, não eram vistos como sujeitos de direitos, mas como objetos dominados pelos pais e excluídos como classe pelas autoridades públicas. Hoje, são considerados como sujeitos de direitos por meio das legislações vigentes; no entanto, há muito a que ser feito para que essa classe seja, no mundo dos fatos, respeitada como tal, pois observa-se que há muitas crianças e adolescentes que diariamente têm seus direitos violados pelo descaso do Estado e da família na qual estão inseridos.

Necessária, portanto, uma conscientização por parte de todos da sociedade no que tange aos direitos da classe infantojuvenil, considerando-os como sujeitos de direitos, haja vista que, por meio de análise dos dados estatísticos 
fornecidos pelo IBGE e pelo Unicef, observa-se que, nas práticas sociais, muitos dos direitos consagrados não são de fato efetivados.

\section{BREVE HISTÓRICO DAS CRIANÇAS E ADOLESCENTES NO BRASIL COLÔNIA}

No Período Colonial, que abrange o século XVIII e meados do século XIX, a constituição familiar era patriarcal, e os pais mandavam e desmandavam na vida da população infantojuvenil, bem como nas esposas e nos seus escravos, ou seja, a dominação era total sob todas as pessoas que viviam sob a autoridade patriarcal.

As crianças e os adolescentes pertencentes a essas famílias patriarcais eram potencialmente amedrontadas, submissas e insignificantes em face da autoridade sem limites do patriarca. O ser criança era visto apenas como um período de transição, sem que houvesse um olhar para as potencialidades daquele indivíduo em condição especial de desenvolvimento. Eram considerados "adultos em miniaturas", não havia um cuidado especial para a classe infantojuvenil, no sentido de atender às suas necessidades em cada fase biológica e natural de sua vida. "No Brasil Colônia, o filho ocupava uma posição secundária na família, uma imagem despida de atrativos tinha direito uma atenção genérica, não personalizada" (Gomes; Jorge, 2008, p. 62).

Neste contexto de negligência havia uma mortalidade infantil acentuada, tendo como um dos fatores a ausência de cuidados especiais com a alimentação das crianças pequenas, ou seja, não havia uma alimentação individualizada e específica, simplesmente os alimentavam com alimentos comuns fornecidos também para os adultos. "O pequerrucho iniciava-se no cardápio familiar, degustando pirões escaldados, peixe cozido, carne desfiada, caldos de panela engrossados com farinha de sessada" (Priore, 2004, p. 89).

Além da alimentação não apropriada para as crianças dentro de sua faixa etária, havia ainda um grande número de mortalidade infantil, devido as inúmeras doenças que assolavam as crianças daquela época, tais como: sarampo, sarna, lombrigas, vermes intestinais, e outras. As causas dessa mortandade infantil eram muitas vezes em virtude da falta de higiene, da falta de antibióticos ou medicação apropriada, do vestuário impróprio, do hábito de mergulhar crianças em água mais ou menos quente, do modo de cortar-se o cordão umbilical empregando-se substância irritante, dos partos mal realizados com parteiras despreparadas, da entrega dos filhos às escravas ignorantes e doentes, dos casamentos consanguíneos que na época era comum, enfim, inúmeras causas que pela ignorância das mães a respeito de como cuidar de seres vulneráveis e dependentes acabavam levando à morte inúmeras crianças. "A ausência de vacinação regular, o limitado conhecimento de doenças contagiosas e as condições de higiene poucos favoráveis, deixavam as crianças a mercê de doenças variadas". (PRIORE, 2004, p. 158). 
Importante ressaltar que, naquela época, as crianças e os adolescentes eram castigados em nome da boa educação, através de palmadas e castigos físicos, "Vícios e pecados, mesmo cometidos por pequeninos deveriam ser combatidos com açoites e castigos" (Priore, 2004, p. 97). Entretanto, tais castigos não se limitavam apenas as crianças, mas também se ampliavam para as mulheres, as quais igualmente vulneráveis sofriam opressão e machismo na sociedade patriarcal da época.

Entretanto, no que tange às crianças pobres e negras, estas ficavam à margem da sociedade, pois a maioria dessas crianças era abandonada nas ruas ou nas rodas dos expostos, instituição pertencente à Santa Casa de Misericórdia, cuja finalidade era dar assistência à criança vinda de uma família miserável, fruto de uma união ilegítima ou de mãe solteira, ou seja, os pais entregavam seus filhos aos cuidados assistencialistas e da caridade cristã para salvá-los da morte (Lima; Veronese, 2011, p. 37).

Entretanto, importante ressaltar que a roda de expostos não era eficiente quanto ao aspecto de assistência social à classe infantil, tendo em vista que a mortalidade infantil era extremamente alta nesse modelo assistencial, tendo como uma das razões o alto número de crianças que se concentrava na instituição. Muitas das crianças acabavam sendo encaminhadas para famílias substitutas, onde eram presas fáceis para o trabalho doméstico, cujos direitos trabalhistas não eram respeitados e garantidos, pois não caracterizava como uma relação trabalhista.

Somente em 1927, com a aprovação do Código de Menores, que as rodas de expostos foram extintas, por meio de movimentos higienistas e por juristas que pretendiam realizar leis eficazes para conter a população infantojuvenil em situação de abandono e com isso diminuir o número de criminalidade em que muitas crianças e adolescentes estavam envolvidos pelo fato de não estarem sob a vigilância da família e do Estado.

Diante dos fatos relatados, percebe-se que, nesse período, não havia uma preocupação especial para com a classe infantojuvenil, em que tanto a família como o Estado não tinham um olhar diferenciado quanto ao aspecto de seu desenvolvimento físico, mental, psicológico, social etc., não eram vistas como seres históricos e sociais como atualmente são considerados - e tal fato de descaso era ainda pior quando se tratava de crianças e adolescentes negros e pobres.

A partir do século $X X$, em meio a muitas descobertas, a grandes inovações tecnológicas e a devastadoras guerras civis e mundiais, as crianças e adolescentes acabam tendo lugar em diplomas legais do mundo e do Brasil, pois passam a ser vistas não como objetos inanimados, mas sim como sujeitos de direitos que possuem os mesmos direitos fundamentais cabíveis aos adultos. Entretanto, muitos dos direitos ainda não estão de forma plena sendo efetivados; hoje temos uma legislação abrangente e satisfatória, porém em muitos casos ineficaz. 
Passa-se a analisar os diplomas legais nacionais e internacionais que irão definir os direitos cabíveis a criança e ao adolescente.

\section{DIPLOMAS LEGAIS PERTINENTES AOS DIREITOS DA CRIANÇA E DO ADOLESCENTE}

\subsection{Declaração de Genebra (1924); Declaração Universal dos Direitos da Criança e a Convenção Internacional dos Direitos da Criança}

A Declaração de Genebra foi realizada em 1924; ela surgiu em virtude das atrocidades cometidas contra as crianças e adolescentes. Durante a Primeira Guerra Mundial, fez a Sociedade de Nações, precursora da atual ONU, adotar a primeira Declaração que acolhesse os direitos pertencentes à classe infantojuvenil, a qual, de forma simples, "assentava as bases para o reconhecimento e a proteção dos direitos da infância, além de cristalizar mudanças em relação à concepção sobre a autonomia e os direitos da criança e do adolescente" (Andrade, 2000, p. 38).

A Assembleia Geral das Nações Unidas adotou, em 1959, uma nova Declaração dos Direitos da Criança, a qual, "além de incorporar novos parâmetros de proteção dos direitos humanos aplicáveis no âmbito da infância e da juventude" (Andrade, 2000, p. 39), buscava ampliar e atualizar a proteção oferecida pela Declaração de Genebra.

A referida Declaração surge devido à necessidade de atender a classe infantil de forma específica, ou seja, leis que digam respeito à criança em suas especificidades, sendo que muitos direitos e liberdades contidos na referida Declaração estão também especificados na Declaração Universal do Homem de 1948. Dessa forma, a Declaração dos Direitos da Criança acaba delimitando a matéria legal no sentido de direcioná-la a classe infantil. Ressalta-se que, com o advento da referida Declaração, reconhece-se a criança como sujeito de direitos.

Em 1989, surge a Convenção Internacional dos Direitos da Criança,

[...] sendo este um resultado de um trabalho de representantes de diversos países que, durante 10 anos, buscaram definir quais os direitos humanos comuns a todas as crianças, capazes de abranger as diferentes conjunturas socioculturais existentes entre os povos, recomendando que a criança seja prioridade imediata e absoluta e reafirmando o princípio do interesse maior da criança [...]. (Firmo, 2005, p. 11)

A referida Convenção foi aprovada pelo nosso Congresso Nacional em 14.09.1990 e promulgada em 21.11.1990 pelo Decreto no 99.710; o Brasil, uma vez ratificando tal diploma internacional, tem o dever legal de atender ao conteúdo que nela vem disposto, pois, caso contrário, não estará respeitando as determinações da Convenção. Entende-se que, sendo uma Convenção, tem 
"natureza coercitiva e exige de cada Estado-parte que a subscreve e ratifica um determinado posicionamento". Portanto, a Convenção tem força de lei internacional, e "cada Estado não poderá violar seus preceitos, como também deverá tomar as medidas positivas para promovê-los" (Veronese, 2003, p. 37).

O preâmbulo da Convenção apresenta princípios básicos para toda e qualquer pessoa, como "a liberdade, a justiça e a paz, os quais reconhecem que toda criatura humana é possuidora de dignidade e de direitos humanos iguais e inalienáveis" (Veronese, 2003, p. 96).

Ademais, a Convenção estabelece critérios universais, ou seja, todos os países que ratificaram a Convenção terão que atender os mesmos direitos ali dispostos, pois se trata de direitos cabíveis a toda e qualquer criança, os quais são básicos e essenciais para o desenvolvimento completo e sadio da classe infantojuvenil - sendo que cada Estado-parte terá que adaptar seus diplomas legais de acordo com o conteúdo da Convenção com a realidade cultural, histórica e econômica de seus países.

Cada Estado tem a Convenção como instrumento básico para todos aqueles que, direta ou indiretamente, trabalham em prol da população infantojuvenil. Reconhece que os direitos inerentes a todas as crianças e adolescentes possuem características específicas devido à peculiar condição de pessoas em desenvolvimento, e que as políticas básicas voltadas à juventude devem agir de forma integrada com a família, a sociedade e o Estado. (Pereira, 2008, p. 310)

A Convenção Internacional dos Direitos da Criança, de um modo geral, possui alguns pontos importantes para o bem-estar da classe infantojuvenil, a fim de que esta possa estar desenvolvendo de forma sadia e completa. Entre os pontos principais, podemos citar: as ações direcionadas às crianças e aos adolescentes deverão ter prioridade atendendo ao seu melhor interesse; que os recursos sejam destinados a medidas necessárias para o bem-estar da criança, sendo necessário recorrer à cooperação internacional (solidariedade entre as nações); garante à criança o direito à vida assegurando a sua sobrevivência e o seu desenvolvimento; a obrigação de o Estado garantir proteção especial a crianças privadas temporária ou permanentemente de suas famílias e assegurar-lhes um ambiente familiar alternativo ou em colocação em instituições apropriadas; adoção das crianças deverá ser feita de acordo com o interesse da criança, que deverá ser revestida de garantias e autorizada pelas autoridades competentes, tendo como inovação a adoção internacional que deverá ser conduzida por autoridades ou organismos competentes; respeito às crianças deficientes (físicas ou mentais), para que tenham uma autonomia e uma vida digna, a fim de que sejam incluídas no meio social, além de outras ações que visem ao bem-estar de todas as crianças e adolescentes.

Importante ressaltar que, na Convenção, surgem princípios que são adotados pelo Brasil, tanto na Constituição Federal de 1988 quanto pelo Estatuto da 
Criança e do Adolescente, como o da prioridade absoluta e o do melhor interesse da criança e, principalmente, a efetivação da Doutrina da Proteção Integral.

\subsection{Constitulção Federal de 1988}

O direito da criança e do adolescente está intimamente ligado com a Constituição Federal, pois, a partir da Carta Magna, é que fluem os direitos fundamentais inerentes a toda e qualquer pessoa, e, também, da população infantojuvenil, bem como há disposição de outros dispositivos legais pertinentes à assistência à criança e ao adolescente. O Professor Custódio reconhece que, com o advento da Constituição, houve a "construção de uma sociedade onde todos poderiam gozar de direitos humanos reconhecidos como fundamentais na nova Constituição que se elaborava. Estava traçada a oportunidade histórica para sepultar o menorismo no Brasil" (2008, p. 26) (grifos nossos).

Com a Constituição Federal, houve uma descentralização de poder, ou seja, forneceu aos Municípios as prerrogativas legais para assumirem decisões de âmbito governamental que atendam aos interesses da criança e do adolescente, no sentido de realizarem políticas públicas que garantam, de forma efetiva, os direitos fundamentais inerentes à classe infantojuvenil.

Tal descentralização é de suma importância, uma vez que os Municípios estão mais próximos dos problemas que assolam a sua comunidade, fato que possibilita realizar ações sociais mais diretivas que venham a solucionar os problemas relacionados à população infantojuvenil. "Assim, a implementação das políticas públicas requer o respeito ao princípio da descentralização político-administrativa, pois essas políticas devem ser realizadas no lugar onde vivem as pessoas" (Custódio, 2008, p. 35).

A Constituição Federal determina que a família, o Estado e a sociedade são corresponsáveis pelas crianças e adolescentes, ou seja, todas as esferas devem estar atentas aos direitos que são cabíveis a essa classe, a fim de que os direitos fundamentais sejam satisfeitos e respeitados, promovendo a dignidade da pessoa humana. Portanto, o art. 227 da CF dispõe:

É dever da família, da sociedade e do Estado assegurar à criança, ao adolescente e ao jovem, com absoluta prioridade, o direito à vida, à saúde, à alimentação, à educação, ao lazer, à profissionalização, à cultura, à dignidade, ao respeito, à liberdade e à convivência familiar e comunitária, além de colocá-los a salvo de toda forma de negligência, discriminação, exploração, violência, crueldade e opressão.

Assim, denota-se, com a leitura do presente artigo, que a Constituição Federal de 1988 adotou o princípio da prioridade absoluta, o qual determina que o Estado, ao realizar políticas públicas, deverá obrigatoriamente atender as demandas e as necessidades primeiramente da classe infantojuvenil, opor- 
tunizando a essa classe a satisfação de seus direitos fundamentais. Leva-se em consideração que as crianças e os adolescentes são pessoas que necessitam de maior atenção, pois se trata de um grupo mais vulnerável que o dos adultos, em virtude de estarem em desenvolvimento físico, mental, emocional etc. e que, portanto, necessitam de um olhar diferenciado.

Neste aspecto, Liberati (2009) comenta que:

A regra constitucional da prevalência do atendimento, apoio e proteção à infância e juventude estabelece a necessidade de cuidar, de modo especial, daquelas pessoas por sua natural fragilidade ou por estarem numa fase em que se completa sua formação com riscos maiores. (p. 16/17)

No mesmo sentido, Firmo (2011) argumenta que as crianças e os adolescentes, sendo incapazes, "física, psicologicamente e juridicamente, de se autotutelarem, constituindo, portanto, uma parte do povo socialmente fraca, surge assim, o fundamento para prever, no ordenamento jurídico, sua tutela [...]" (p. 22).

Hoje não se considera mais a criança e o adolescente como "objetos", mas sim como sujeitos de direitos, que possuem desejos, vontades e opiniões próprias. Portanto, não há mais a coisificação da população infantil, como ocorria em épocas antigas, e sim pessoas que estão em desenvolvimento e que necessitam de uma proteção especial e prioridade absoluta em face de toda e qualquer ação governamental.

Importante ressaltar que a prioridade absoluta não se refere apenas ao Estado para com a criança e ao adolescente, mas tal prioridade também é obrigatoriedade da família e da sociedade. A família tem o dever legal de orientar, cuidar, alimentar, preservar e educar sua prole, a fim de que esta consiga desenvolver-se plenamente e esteja preparada para a vida em todos os aspectos, bem como realizar um planejamento familiar, sendo que o casal deve ter filhos desejados, e que tenham maturidade emocional e condições econômicas para tê-los.

No que tange à sociedade, esta deve estar presente em todos os momentos, com ideias e medidas eficazes para assegurar os direitos fundamentais das crianças e adolescentes, bem como colaborar como o Poder Público, por meio de associações civis, na melhoria da qualidade de vida de milhares de crianças que se encontram em situação de risco, ou que tenham seus direitos diariamente sendo violados. Neste sentido, Custódio (2008) argumenta que:

A construção de um projeto emancipador que torne possível uma nova perspectiva de cultura política encerra em si a questão da participação. As ações da sociedade civil vêm ganhando corpo e legitimidade, principalmente nos últimos anos, em decorrência da conquista de novos espaços sociais e de uma postura crítica positiva em relação aos papéis que devem ser desempenhados pelo Estado. (p. 36) 
Não há dúvidas de que tanto o Estatuto quanto a Constituição Federal possuem caráter jurídico-garantista, pois a família, o Estado e a sociedade possuem o dever legal de assegurar a efetivação dos direitos fundamentais referentes à classe infantojuvenil, no sentido de que estes direitos sejam respeitados e concretizados, que não permaneçam apenas na teoria.

Assim, a Constituição Federal de 1988 contém normas que estão impregnadas de princípios internacionais dos direitos humanos, os quais foram incorporados no corpo constitucional, reconhecendo crianças e adolescentes como sujeitos de direitos, que necessitam de uma proteção especial e integral pelo fato de estarem em pleno desenvolvimento biopsicossocial.

\subsection{Estatuto da Criança e do Adolessente (Lel no 8.069/1990)}

O Estatuto da Criança e do Adolescente surge com o intuito de proteger a classe infantojuvenil de forma especial, pois a considera como pessoas em desenvolvimento, reconhecendo-a com suas próprias especificidades, e que, para tanto, necessitam de um cuidado e olhar diferenciado. E, nesse sentido, o Estatuto vem reforçar o que já está previsto no art. 227 da CF, quando refere-se à proteção dos direitos fundamentais da criança e do adolescente, proibindo enfaticamente qualquer discriminação a essa classe infantojuvenil. O Estatuto, portanto, possui a função de tutelar a população infantojuvenil, protegendo-a contra toda e qualquer forma de violência, discriminação, exploração, crueldade e opressão, que afete o princípio da dignidade da pessoa humana, o qual vem consagrado na Constituição Federal.

No art. $3^{\circ}$ do Estatuto, define os direitos fundamentais da classe infantojuvenil, os quais não diferem daqueles cabíveis aos adultos, bem como adota a doutrina da proteção integral e o da prioridade absoluta, que vem disposto no art. $4^{\circ}$ do Estatuto:

Art. $3^{\circ}$ A criança e o adolescente gozam de todos os direitos fundamentais inerentes à pessoa humana, sem prejuízo da proteção integral de que trata esta lei, assegurando-se-lhes, por lei ou por outros meios, todas as oportunidades e facilidades, a fim de lhes facultar o desenvolvimento físico, mental, moral, espiritual e social, em condições de liberdade e de dignidade.

Art. 4⿳㇒ É dever da família, da comunidade, da sociedade em geral e do poder público assegurar, com absoluta prioridade, a efetivação dos direitos referentes à vida, à saúde, à alimentação, à educação, ao esporte, ao lazer, à profissionalização, à cultura, à dignidade, ao respeito, à liberdade e à convivência familiar e comunitária.

Importante evidenciar que a doutrina da Proteção Integral foi adotada pelo Brasil em virtude da Convenção Internacional sobre os Direitos da Criança, portanto trata-se de um princípio internacional, em que todos os que aderem à referida Convenção terão que respeitá-la e acrescentá-la no ordenamento legal. 
A Doutrina da Proteção Integral assegura um direito universal às crianças e adolescentes e esse direito não deve e não pode ser exclusivo de uma categoria de menor, classificado como carente, abandonado o infrator, mas deve dirigir-se a todas as crianças e a todos os adolescentes sem distinção. (Liberati, 2009, p. 14)

Neste aspecto, percebe-se que o Estatuto e a Constituição Federal estabelecem esta doutrina como fator preponderante na defesa dos direitos da população infantojuvenil, tutelando essa classe em todos os aspectos, bem como zelando por todas as crianças de forma igual, sem discriminações, não mais utilizando o termo "menor" como outrora era utilizado, de forma pejorativa e discriminatória. Tais diplomas legais tutelam crianças e adolescentes independentemente da classe social em que se encontram, ou seja, toda a classe infantojuvenil deverá ser protegida seja rico, pobre, infrator, estando ou não em situação de risco. Custódio (2008) ensina que:

A teoria jurídica do direito do menor desempenhava papel especial na ressignificação da realidade, pois dispunha de um aparato capaz de transformar o menino e a menina pobre em "menor em situação de risco" e, portanto, destinatário da responsabilização individua pela sua própria condição de irregularidade. Era a construção de um mundo paralelo, onde a irregularidade era imaginada com base em preconceitos e estereótipos e depois restava aos agentes do Estado enquadrar o público perfeito à caracterização da barbárie. (p. 25)

Lembrando que, anteriormente à Constituição Federal de 1988 e ao Estatuto da Criança e do Adolescente, havia arraigada no Brasil a Doutrina da Situação Irregular, que surgiu com o advento do Código de Menores de 1927, e, posteriormente, com o Código de Menores de 1979, sendo que, neste último diploma legal, adotou-se, de forma expressa, a referida Doutrina, em que havia uma "visão estigmatizada de infância e juridicamente era aprisionada pelos conceitos positivistas clássicos de menoridade" (Custódio, 2008, p. 24).

Denota-se que havia a concepção de que a população infantojuvenil deveria receber apenas assistência, considerando somente as crianças e os adolescentes abandonados ou infratores; não havia uma correlação da situação irregular com o sistema econômico e a desigualdade social que assolava o País. Percebe-se que o Estado desejava se eximir frente à situação calamitosa em que se encontravam inúmeras crianças e adolescentes.

O advento da Doutrina da Proteção Integral foi uma ruptura histórica relativa ao tema criança e adolescente. Custódio (2008) ensina que tal Doutrina surge como uma

força capaz de varrer todos os pressupostos teóricos da doutrina da situação irregular, primeiro contestando sua própria validade científica, e depois formulando um conjunto de conceitos operacionais, regras, sistemas integrados e articulados em rede que tornaram absolutamente incompatível a congruência de um modelo com o outro. (p. 23) 
O direito da criança e do adolescente é pautado também no princípio do melhor interesse da criança, ou seja, todas as ações que digam respeito à garantia de direitos fundamentais da classe infantojuvenil devem estar centradas no melhor interesse dessa classe; tal princípio é de fundamental importância no que tange à realização de políticas públicas que terão sempre em pauta o melhor interesse da criança e do adolescente.

\section{A Professora Pereira (2008) afirma que}

o Brasil incorporou, em caráter definitivo, o princípio do melhor interesse da criança em seu sistema jurídico e, sobretudo, tem representado um norteador importante para a modificação das legislações internas no que concerne à proteção da infância em nosso continente. (p. 01)

Importante ressaltar que o Estatuto da Criança e do Adolescente, ao definir as políticas de atendimento a crianças e adolescentes, determinou que tais políticas deverão ser realizadas por meio de ações articuladas, ou seja, todas as esferas governamentais, União, Estado e Municípios, bem como esferas não governamentais, deverão realizá-las em prol da população infantojuvenil, no sentido de efetivação de todos os direitos fundamentais elencados no próprio Estatuto da Criança e do Adolescente e na Carta Magna.

No art. 88 do Estatuto da Criança e do Adolescente foram elaboradas as diretrizes de política de atendimento dos direitos da criança e do adolescente, tendo como um dos princípios basilares a descentralização político-administrativa, em que o Município, como pessoa autônoma, deixa de ser mero executor das políticas traçadas pela União e Estados, tendo a iniciativa de "ditar qual o melhor método de aplicação e de desenvolvimento das diretrizes por ele traçadas" (Liberati, 2009, p. 85).

Cada município terá Conselhos Municipais de Direitos, o Fundo Municipal e o Conselho Tutelar, sendo que todos deverão estar trabalhando conjuntamente para a realização de políticas sociais destinadas ao melhor interesse da população infantojuvenil. Tais entidades são responsáveis também pela defesa dos direitos fundamentais dessa população e devem estar em sintonia para que cada um dentro de suas funções específicas proporcionem uma melhor qualidade de vida a todas as crianças e adolescentes, independentemente de cor, sexo, condição social ou econômica.

Portanto, tanto a Constituição Federal quanto o Estatuto da Criança e do Adolescente estabelecem princípios, como do melhor interesse da criança e o da prioridade absoluta, os quais se encontram pautados na Doutrina da Proteção Integral, que rege todo o ordenamento jurídico referente aos direitos da classe infantojuvenil. Defende a ideia de que crianças e adolescentes devem ser tratados como sujeitos de direitos, ou seja, cidadãos como qualquer pessoa adulta. E, ainda, como grupo vulnerável, que necessita de uma maior e especial atenção, no que tange à condição de estarem em desenvolvimento biopsicos- 
social. Nesse sentido, possuem necessidades especiais e imediatas, para serem atendidas conjuntamente pela família, Estado e sociedade.

\section{A CRIANÇA E O ADOLESCENTE COMO SUJEITOS DE DIREITOS}

Com o advento da Constituição Federal e do Estatuto da Criança e do Adolescente, as crianças e os adolescentes passam a ser sujeitos de direitos, ou seja, passam a ter direitos como qualquer pessoa adulta, e tais direitos são reconhecidos pelo ordenamento jurídico vigente, não são mais vistos objetos como outrora eram vistos. Por mais que não possuam completamente a capacidade civil, são pessoas que ostentam, como titulares, prerrogativas inerentes ao exercício dos direitos fundamentais - lembrando, neste aspecto, que possuem proteção desde o ventre da mãe, possuem direito de desenvolver e nascer de forma saudável.

Rossato, Lépore e Sanches (2012) afirmam que

tal conclusão encontra guarida no inciso IV do art. $3^{\circ}$ da CF, que determina ser objetivo fundamental da República Federativa do Brasil promover o bem de todos, sem preconceitos de origem, raça, sexo, cor, idade e quaisquer outras formas de discriminação. (grifos nossos - p. 95)

Ou seja, independentemente da idade, toda e qualquer pessoa humana deverá gozar, de forma plena, os direitos elencados nos diplomas legais, a fim de que possam ter condições para terem uma vida digna em sociedade, como determina o nosso Estado Democrático de Direito.

O Estatuto da Criança e do Adolescente, no seu Titulo II, estabelece uma série de direitos fundamentais que são cabíveis à classe infantojuvenil; assim, percebe-se que o legislador quis garantir a essa classe não somente direitos que são cabíveis ao mundo dos adultos, mas também garantir direitos especiais que atendam e assegurem o desenvolvimento sadio e pleno dessa parcela da população. Como bem ensina Fonseca (2001): "[...] o Estatuto da Criança e do Adolescente arrola direitos fundamentais fundados na dignidade da pessoa humana em geral, mas sob a ótica da criança e do adolescente, em particular $[\ldots]^{\prime \prime}($ p. 41).

Importante ressaltar que os direitos fundamentais das crianças e dos adolescentes são direitos de alcance heterogêneo, pois dizem respeito a uma classe específica de pessoas, tendo em vista que tal heterogeneidade tem razão de ser, pois a classe infantojuvenil é considerada vulnerável em meio à sociedade, portanto, merecedora e carecedora de proteção legal específica. Neste sentido, Rossato, Lépore e Sanches (2012) afirmam que "a comunidade internacional reconheceu que as crianças necessitam de atenção especial que as preserve das consequências danosas, derivadas de situações que podem colocá-las em risco" (p. 58). 
Assim, percebe-se que os inúmeros documentos nacionais e internacionais que garantem os direitos da criança e do adolescente são heterogêneos, os quais se preocupam com os indivíduos que estão em desenvolvimento e que, por isso, necessitam de uma maior proteção legal, bem como um olhar diferenciado, por estarem em uma posição de vulnerabilidade ou hipossuficiência. Entretanto, ao analisar a situação real de muitas crianças e adolescentes em nosso Brasil, percebe-se que ainda tem muito há fazer no que tange à efetivação desses direitos por meio de políticas públicas no campo da saúde e do social.

Constata-se, em meio à sociedade, que ainda existe o descaso por parte dos governantes com o respeito aos direitos da população infantojuvenil, haja vista que, no Brasil, há uma grande desigualdade social, em que a classe pobre ou miserável não é conhecida como tal, passando despercebida pela maioria da população de classe média e alta e pelo próprio Poder Público. E, nesse contexto social, as maiores vítimas são as crianças e adolescentes que são estigmatizados e condenados, na maioria dos casos, a permanecer na mesma miséria que a dos seus pais.

Os direitos fundamentais estão especificados de forma bastante satisfatória e significativa no Estatuto e na Constituição Federal, ou seja, o ser criança é protegido desde a fase embrionária, fato importantíssimo para diminuir o número de mortalidade infantil, bem como o nascimento e o desenvolvimento de crianças mais saudáveis. Importante destacar, neste aspecto, que o Brasil reduziu, de forma significativa, a mortalidade infantil, pois, conforme dados do Unicef, a taxa de mortalidade infantil caiu de 47,1/1000 para 19/1000, em 2008. Porém, no mesmo documento constata-se que as crianças pobres têm mais do que o dobro de chance de morrer, em comparação às ricas, e, no caso de crianças negras, 50\% a mais em relação às brancas. Ou seja, identifica-se nestas estatísticas que as crianças pobres e negras acabam sendo as maiores vítimas da mortalidade por suas condições desiguais no âmbito social.

De acordo com o estudo realizado pelo IBGE, no que tange à mortalidade infantil, constata-se que o Nordeste é uma região em que a população encontra-se marginalizada, não tendo acesso a uma renda mínima para a sua sobrevivência, bem como carente de uma infraestrutura adequada de saneamento e de saúde, fato que leva à morte inúmeras crianças. Tal estudo defende a ideia de ações políticas e sociais na área da saúde capazes de agilizar o processo de queda do número de mortalidade infantil na região Nordeste, bem como uma distribuição de renda mais equitativa de recursos na área da saúde, promovendo a redução das desigualdades regionais e sociais (1999, p. 36).

Com relação à desnutrição, verifica-se, por meio dos dados do Unicef, que ela ainda está presente no Brasil, pois cerca de 60 mil crianças com menos de um ano de idade são desnutridas, ou seja, a falta de uma alimentação adequada e nutritiva para muitas crianças em tenra idade é chocante, afetando inúmeras famílias brasileiras e comprometendo o desenvolvimento sadio delas. 
Tal situação calamitosa fere diretamente o princípio da dignidade da pessoa humana, entre outros que são estabelecidos na Carta Magna.

Atualmente o Brasil possui leis nacionais e internacionais que atendem aos interesses da classe infantojuvenil, o que não existia em épocas atrás. Contudo, ainda temos muito descaso para com essa classe considerada especialmente vulnerável às violações de direitos, à pobreza e às iniquidades em nosso País. No Brasil, de acordo com dados do Unicef, temos 190 milhões de brasileiros, dos quais 60 milhões são menores de dezoito anos, ou seja, 60 milhões de pessoas que necessitam de uma maior atenção e cuidados especiais por estarem em condição peculiar, qual seja, em desenvolvimento biopsicossocial.

É clarividente que a situação mudou muito do Brasil Colônia até os dias atuais, principalmente no campo legislativo; entretanto, ao se referir em políticas sociais direcionadas a essa classe, as quais permitirão que os direitos fundamentais sejam realmente satisfeitos no mundo real, o país ainda precisa melhorar, principalmente quando se analisa a questão das crianças negras e pobres que, diga-se de passagem, são duplamente discriminadas pelo fato de ser criança e pelo fato de ser negra ou pobre. Lima e Veronese (2011) argumentam que

a história social de formação do Estado brasileiro, desde o período colonial, é reveladora das profundas desigualdades sociais vivenciadas entre o seu povo. A produção normativa teve como uma de suas funções o exercício do controle social das camadas empobrecidas da população, escamoteado por interesses políticos e econômicos. (p. 139)

De acordo com dados do Unicef, $29 \%$ da população vive em famílias pobres, mas, entre as crianças, esse número chega a 45,6\%; no que tange à criança negra, tem quase $70 \%$ mais chance de viver na pobreza do que as brancas. Quanto às crianças que vivem na região do semiárido, trata-se de 13 milhões de crianças, sendo que mais de $70 \%$ das crianças e dos adolescentes são classificados como pobres. Observa-se que, no Brasil, temos várias infâncias, as quais não são atendidas de forma satisfatória e diferenciadas, na maioria dos casos, pelo Poder Público, pela sociedade e pela própria família na qual estão inseridos.

Outro fato a destacar é com respeito ao direito à educação, em que se verifica, por meio de dados do Unicef, que muitas crianças estão fora da escola, em que $64 \%$ das crianças pobres não vão à escola durante a primeira infância, em que aproximadamente uma em cada quatro crianças de 4 a 6 anos de idade não estão na escola. Quanto às crianças de 7 a 14 anos de idade, o Brasil tem 535 mil crianças fora da escola, das quais 330 mil são negras. Nas regiões Norte e Nordeste, somente $40 \%$ concluem o ensino fundamental, e, nas regiões mais desenvolvidas, Sul e Sudeste, essa proporção chega a 70\%, números que pro- 
vam que existe uma grande disparidade com relação à situação das crianças e adolescentes dependendo da região onde estão locadas.

Através desses dados constata-se que o direito à educação como direito fundamental não está sendo garantido de forma plena, principalmente para as classes pobres e negras, as quais são vítimas do preconceito de toda uma população, e desprezadas enquanto classe por parte dos Poderes Públicos, que deveriam efetivar esse direito, que é universal, ou seja, cabível a qualquer pessoa independente de raça, cor, sexo, condição física ou econômica. Observa-se também que os Poderes Públicos não levam em conta as disparidades regionais que existem no Brasil, tendo em vista que cada região possui suas necessidades e mazelas específicas, as quais deverão ser atendidas com políticas sociais diretivas, a fim de solucionar os problemas que afetam as pessoas que moram naquelas regiões.

Considerando que as regiões Norte e Nordeste são regiões menos desenvolvidas e que necessitam de uma maior atenção por parte dos governantes - pois nessas regiões concentram-se os maiores problemas sociais, como mortalidade infantil, desnutrição, evasão escolar, fome, desemprego, entre outras -, por isso a importância de políticas públicas específicas e ações afirmativas que possam diminuir as desigualdades existentes entre essas regiões com relação às outras regiões consideradas mais desenvolvidas.

Importante destacar também a questão da violência contra crianças e adolescentes, um problema que desrespeita, de forma direta, uma série de direitos fundamentais, sendo que, na maioria dos casos, os principais agressores são os próprios pais, que utilizam do pátrio poder para castigar e violentar seus filhos, os quais são vítimas de violência física, psicológica e sexual - em que, na maioria dos casos, ocorre um pacto de silêncio entre as vítimas e seus algozes, sendo que tal silêncio dificulta a punição dos culpados pelas barbaridades cometidas contra suas pequenas vítimas.

Dados fornecidos pelo Unicef apontam um cenário desolador em relação à violência contra a classe infantojuvenil, em que, a cada dia, 129 casos de violência psicológica, física, sexual e a negligência contra crianças e adolescentes são reportados, em média, ao Disque Denúncia 100. Isso quer dizer que, a cada hora, cinco casos são de violência contra a população infantojuvenil. Tal cenário ainda pode ser mais grave se levar em consideração as denúncias que não são feitas pelo medo que as vítimas sentem e até mesmo pelo sentimento de vergonha e culpa que muitas dessas crianças e adolescentes apresentam em face de seus agressores.

Diante dos dados demonstrados, percebe-se que a maioria das crianças e adolescentes, mais precisamente os pobres e negros, não são considerados como sujeitos de direitos, pois há descaso por parte do Poder Público em dar assistência e assegurar que os direitos consagrados nos diplomas legais sejam realmente efetivados em meio à sociedade. Importante salientar que não basta 
ter direitos, mas que estes sejam efetivados, a fim de que a classe infantojuvenil possa desenvolver-se plenamente no meio em que vivem, seja no Norte, Nordeste, Sul, Sudeste ou Centro-Oeste.

Infelizmente, vivemos num país onde continua a existir uma gritante desigualdade social e econômica, em que as maiores vítimas desse descaso por parte das autoridades públicas são as crianças e os adolescentes, os quais necessitam do ser adulto para oferecer-lhes proteção, cuidados, afeto, segurança, para que possam, num futuro próximo, tornarem-se adultos sadios e seguros. Dessa forma, observa-se que há, sem dúvida, um "conjunto normativo e uma doutrina jurídica avançada que precisa urgentemente refletir-se nas práticas sociais" (Lima; Veronese, 2011, p. 128).

Entretanto, a questão histórica leva-nos a entender o porquê de tanta violência, descaso e negligência que ainda assolam inúmeras crianças e adolescentes em nosso país, não somente por parte das famílias, que são corresponsáveis pelo bem-estar e efetivação de seus direitos fundamentais, mas também por parte dos Poderes Públicos, que não realizam políticas públicas suficientes e satisfatórias para atenderem às necessidades dessa classe infantojuvenil.

Observa-se que esse cenário de descaso com os direitos da criança e do adolescente é uma questão cultural e social em que continua arraigada em nosso país, apenas de forma modificada, em que a maioria das famílias não deixaram de ser patriarcais, pois ainda se utilizam os seus filhos como se fossem propriedades suas, continuam tratando-os como objetos, cujas mães continuam abandonando seus filhos a própria sorte, não mais nas rodas dos expostos porque não existe mais esta prática, pois, se existisse, haveria o abandono -, mas em latas de lixo ou nas ruas. Não há, muitas vezes, uma conscientização das pessoas adultas quanto ao fato de que a classe infantojuvenil possui direitos fundamentais como qualquer ser adulto, e que hoje, com o advento da Constituição Federal e do Estatuto da Criança e do Adolescente, essa classe é considerada como sujeito de direitos.

Os direitos fundamentais da classe infantojuvenil, indubitavelmente, foram uma conquista histórica, em que a sociedade organizada na defesa dos direitos dessa classe lutou por décadas com o objetivo de que crianças e adolescentes tivessem voz em meio à sociedade e pudessem ser reconhecidas e respeitadas como verdadeiros cidadãos, como qualquer ser adulto. Infelizmente, tem-se muito há fazer para que tais direitos sejam colocados em prática e se concretize, a fim de que a criança possa ser vista como um indivíduo pensante, crítico, social e histórico.

\section{CONSIDERAÇÕES FINAIS}

Ao analisar historicamente a proteção jurídica da classe infantojuvenil, constatamos que sempre foi marcada pela exclusão e descaso por parte das au- 
toridades públicas, pela família e pela sociedade. As crianças e os adolescentes sempre foram coisificados, eram propriedades de seus pais, os quais tinham poder de vida e morte sobre seus filhos, enquanto o Estado eximia-se de sua responsabilidade transferindo-a para a Igreja; não eram vistos como indivíduos autônomos, pensantes, críticos e, sobretudo, humanos. Tal fato se agravava quando crianças e adolescentes eram pobres ou negros, os quais eram as maiores vítimas do abandono e do descaso por parte do Estado e da família, pois eram entregues a instituições de assistência social, ou seja, nas rodas dos expostos.

Hoje, indubitavelmente, temos uma legislação consistente e ampla que trata dos direitos fundamentais das crianças e dos adolescentes, considerando-os como sujeitos de direitos e não mais como "coisas", mas, por outro lado, há muitas crianças e adolescentes que diariamente têm seus direitos violados e afrontados nos seus direitos enquanto cidadãos e enquanto novos sujeitos de direitos, pelas instituições que deveriam dar-Ihes segurança, respeito, cuidado, ou seja, a família, a sociedade e o Estado, os quais são corresponsáveis pelo bem-estar da população infantojuvenil, segundo a Constituição Federal de 1988, mas que ainda não se adaptaram à nova realidade jurídica, política e social que o Estatuto determina em seu corpo normativo.

Ao analisarmos as estatísticas fornecidas pelo Unicef e pelo IBGE, constatamos que ainda há muito o que fazer para que os direitos elencados na Constituição Federal e no Estatuto da Criança e do Adolescente sejam efetivamente respeitados por parte de todos os indivíduos, pois percebe-se que ainda há o ranço do menorismo em nossa sociedade brasileira, bem como a cultura patriarcal em muitas famílias. E a situação piora quando crianças e adolescentes estão inseridos na classe pobre e negra, pois são constantemente vítimas do preconceito e da omissão por parte do Estado na realização de políticas sociais mais diretivas e específicas que atendam, de forma significativa, a essa demanda da população carente, a fim de que haja uma compensação dessa triste desigualdade.

A miséria em que se encontram muitas famílias faz crianças e adolescentes, desde muito cedo, trabalharem para complementar a renda familiar, deixando de lado a escola, o lazer, em prol do sustento delas mesmas e de sua família. Assim, o grande problema para que haja uma real efetivação dos direitos fundamentais garantidos nos diplomas legais nacionais e internacionais está na questão da miséria que assola a grande maioria da população brasileira, que está privada do acesso a bens materiais e morais que estão presentes em nossa sociedade.

Observa-se, em meio à sociedade brasileira, que o abandono, a agressão, a exploração contra crianças e adolescentes ainda existem de forma bastante significativa; a única diferença é que antigamente não havia uma legislação específica que atendia aos interesses das crianças e adolescentes, bem como estes não eram considerados como sujeitos de direitos, fato que torna nossa 
realidade social melhor no sentido de que temos instrumentos legais para punir os agressores e garantir que os direitos sejam preservados.

Entretanto, não basta ter direitos se não conseguimos satisfazê-los! Continua-se a desrespeitar essa classe que precisa dos adultos para se desenvolver de forma saudável e segura. Afinal, a criança e o adolescente estão sendo vistos e respeitados como sujeitos de direitos? Tal resposta surgirá apenas se olharmos criticamente a realidade social em que vivemos, e não nos acomodemos por termos uma legislação abrangente e detalhada sobre os direitos da criança e do adolescente, mas que no mundo real não há um efetivo cumprimento legal.

\section{REFERÊNCIAS}

ANDRADE, Anderson Pereira de. A convenção sobre os direitos da criança em seu décimo aniversário: avanços e efetividade e desafios. Revista Ministério Público Distrito Federal, Brasília, n. 03, p. 37-52, 2000. Disponível em: <http://www.mpdf+gov.br/revistas/index.php/ revistas/article/viewfile/89/104>. Acesso em: 30 mar. 2013.

ARIÈS, Philippe. História social da criança e da família. Rio de Janeiro: LTC, 2012.

BRASIL. Constituição Federal do Brasil de 1988.

. Estatuto da Criança e do Adolescente: Lei no 8.069/1990. Disponível em: http// www.planalto.gov.br. Acesso em: 10 fev. 2013.

CUSTÓDIO, André Viana. Teoria da proteção integral: pressuposto para compreensão do direito da criança e do adolescente. Revista de Direito, v. 29, p. 22-43, 2008. Disponível em: <http//online.unisc.br/seer/índex.php/direito/article/viewfile/657/454>. Acesso em: 23 maio 2013.

FIRMO, Maria de Fátima Carrada. A criança e o adolescente no ordenamento jurídico brasileiro. Rio de Janeiro: Renovar, 2005.

FONSECA, Antonio Cezar Lima da. Direitos da criança e do adolescente. São Paulo: Atlas, 2001.

GOMES, Ilvana Lima Verde; CAETANO, Rosangela; JORGE, Maria Salete Bessa. Criança e seus direitos na família e na sociedade: uma cartografia das leis e resoluções. Revista Brasileira de Enfermagem - Reben, Brasília, jan./fev. 2008. Disponível em: <http://www.scielo.br/ pdf/reben/v.61n1/09.pdf>. Acesso em: 28 mar. 2013.

INSTITUTO Brasileiro de Geografia e Estatística - IBGE. Evolução e perspectivas da mortalidade infantil no Brasil. Rio de Janeiro, 1999. Disponível em: <http//www.ibge.gov.br/home/ estatística/população/evoluções_perspectivas_mortalidade/evolução_mortalidade>. Acesso em: 13 jun. 2013.

LIBERATI, Wilson Donizeti. Direito da criança e do adolescente. São Paulo: Rideel, 2009.

LIMA, Fernanda da Silva; VERONESE, Josiane Rose Petry. Mamãe África, cheguei ao Brasil: os direitos da criança e do adolescente sob a perspectiva da igualdade racial. Florianópolis: Editora da UFSC: Fundação Boiteux, 2011.

MARCILIO, Maria Luiza. A lenta construção dos direitos da criança brasileira século XX. Revista USP, p. 46-57, mar./abr./maio 1998. Disponível em: <http://www.gov.ufsc.br/portal/ sites/default/files/anexos/28330-28350-1-pb.pdf>. Acesso em: 10 abr. 2013.

PEREIRA, Tânia da Silva. O reconhecimento dos direitos fundamentais da criança e do adolescente nos sistema jurídico Brasileiro. In: MATOS (Org.). A construção de novos direitos. Porte Alegre: Núria Fabris, 2008. 
PRIORE, Del Mary. História das crianças no Brasil. São Paulo: Contexto, 2004.

RIZZINI, Irene; PILOTTI, Francisco. A arte de governar crianças: a história das políticas sociais, da legislação e da assistência à infância no Brasil. São Paulo: Cortez, 2009.

ROSSATO, Luciano Alves; LÉPORE, Paulo Eduardo; CUNHA, Rogério Sanches. Estatuto da Criança e do Adolescente comentado: Lei no 8.069/1990. Artigo por artigo. São Paulo: Revista dos Tribunais, 2012.

SILVA, Moacyr Motta da; VERONESE, Josiane Rose Petry. A tutela jurisdicional dos direitos da criança e do adolescente. São Paulo: LTr, 1998.

UNICEF. Infância e adolescência. Disponível em: <http://unicef.org/brazil/pt/activities.html>. Acesso em: 10 jul. 2013.

VERONESE, Josiane Rose Petry. Os direitos da criança e do adolescente: construindo o conceito de sujeito-cidadão. In: WOLKMER, Antonio Carlos; LEITE, José Rubens Morato. Os novos direitos no Brasil: natureza e perspectivas: uma visão básica das novas conflituosidades jurídicas. São Paulo: Saraiva, 2003. 